https://helda.helsinki.fi

\title{
Negatives without negators
}

\section{Miestamo, Matti}

De Gruyter Mouton

2010

Miestamo , M 2010 , Negatives without negators . in J Wohlgemuth \& M Cysouw (eds), Rethinking universals : How rarities affect linguistic theory. Empirical Approaches to Language Typology , vol. 45 , De Gruyter Mouton , Berlin , pp. 169-194 . https://doi.org/10.1515/9783110220933.16

http://hdl.handle.net/10138/154090

https://doi.org/10.1515/9783110220933.169

acceptedVersion

Downloaded from Helda, University of Helsinki institutional repository.

This is an electronic reprint of the original article.

This reprint may differ from the original in pagination and typographic detail.

Please cite the original version. 


\title{
Negatives without negators
}

\author{
Matti Miestamo
}

\section{Introduction}

Das grammatische Raritätenkabinett ${ }^{1}$ assembled by Frans Plank features the following rarum concerning the expression of clausal negation (number 33):

"negation expressed negatively, by omission of material present in affirmative clause".

Well-known instances of this so-called Zero Negative construction are found in some Dravidian languages in which negation can be signaled by the mere absence of tense marking without an overt marker of negation. In this paper, I take a look at this rare type of negative construction from a typological perspective.

Section 2 briefly introduces the Dravidian Zero Negative construction. Section 3 discusses the phenomenon in a cross-linguistic perspective, suggesting possible typological parallels to the absence of tense and negation markers. Section 4 addresses the possibility of ellipsis of negators in languages in which these are usually present in the negative construction. Section 5 first discusses whether and how the absence of tense and negation markers is functionally motivated and examines then the implications of negatives without negators to the markedness of negation vis-à-vis affirmation. Section 6 offers a brief conclusion.

\section{The Dravidian zero negative}

The Dravidian zero negative (Master 1946), reported from (earlier stages) of many South and Central Dravidian languages, is a negative construction in which negation is expressed without an overt marker of negation, by the mere absence of tense marking present in the corresponding affirmatives. The affirmative verb forms can be rendered schematically as ROOT-TENSE-PERSON and the negative ones as ROOT-PERSON. In Old Kannada, for example, we find the affirmative-negative correspondences in (1). 
(1) Old Kannada (India; Dravidian: Southern Dravidian) (Pilot-Raichoor (2010: 268-269) ${ }^{2}$
a. no:di-uv-em
see-FUT-1SG
'I will see'
b. no:d-id-em see-PST-1SG
'I saw'
c. no:d-em see-1SG
'I do/ did / will not see'

As can be seen in (1), there is no overt marker of negation, and the negative (1c) differs from the corresponding affirmatives (1a) and (1b) only by the presence vs. absence of tense marking. The tense distinction made in the affirmative is lost in the negative.

I will not engage in a detailed description of Zero Negatives in different Dravidian languages (see Masters (1946); Subrahmanyam (1971); Pederson 1993; Pilot-Raichoor (1997, 2010) for more detailed data and analysis); the brief characterization given here should suffice as a basis for the typological discussion that I now turn to.

\section{Typological parallels}

More generally, the Dravidian Zero Negatives may be seen as instances of a construction type in which no overt marker of negation appears and the negative differs from the corresponding affirmative by the absence of marking of a category (or categories) present in the affirmative (be it tense or any other category). This construction type can be called the Subtracting Zero Negative Construction.

In my typological study of standard negation - the basic strategies languages use for negating declarative verbal main clauses (Miestamo 2005) not a single language in an areally and genealogically representative variety sample of 297 languages shows this type of construction. There are three Dravidian languages in the sample, Brahui, (Modern) Kannada and Malayalam, but none of these languages have a productive Subtracting Zero Negative Construction according to my sources.

Outside of the Dravidian family, I am not aware of any languages showing this type of construction, either. This section discusses some typological parallels, i. e. structures that have some properties in common with the Dravidian Zero Negatives (or more generally, with the Subtracting Zero Negative Construction). There are two basic aspects that need to be discussed: that the marking of tense or some other categories is absent (Section 3.1), and that there is no overt marker of negation (Section 3.2). 


\subsection{Absence of tense marking}

The absence of tense marking in the negative is better understood in the context of the distinction between symmetric and asymmetric negation (Miestamo 2005). Negatives can be divided into two basic types, symmetric and asymmetric, according to whether and how the structure of the negative differs from the structure of the affirmative in addition to the presence of negative markers. The symmetry-asymmetry distinction can be observed in constructions and paradigms.

In a symmetric negative construction, the negative does not differ structurally from the corresponding affirmative in any other way than by the presence of the negative marker(s), e. g., in German (2), where the presence of nicht is the only structural difference between negatives and affirmatives.

(2) German (Germany; Indo-European: Germanic) (constructed example)

a. singen 'to sing', $1 \mathrm{SG}$

AFFIRMATIVE NEGATIVE

PRES ich singe ich singe nicht

PST ich sang ich sang nicht

PERF ich habe gesungen ich habe nicht gesungen

PLUPERF ich hatte gesungen ich hatte nicht gesungen

b. singen 'to sing', $2 \mathrm{SG}$

$\begin{array}{lll} & \text { AFFIRMATIVE } & \text { NEGATIVE } \\ \text { PRES } & d u \text { singst } & d u \text { singst } \text { nicht } \\ \text { PST } & \vdots & \vdots\end{array}$

In an asymmetric negative construction the structure of the negative differs from the structure of the corresponding affirmative in other ways (as well), i. e. not (merely) by the presence of the negative marker(s), e.g., in Finnish cf. (3) on this page, where the negative marker is the negative auxiliary $e$ carrying personal inflections, and the lexical verb appears in the non-finite Connegative form.

(3) Finnish (Finland; Uralic: Finnic) (constructed example)
a. laula-n
sing-1SG
b. e-n laula
NEG-1SG sing.CNG
'I sing.'
'I do not sing.'

In a symmetric paradigm the correspondences between the paradigms used in affirmatives and negatives are one-to-one, e. g., in German (2), where 
all affirmative declaratives, regardless of the choice of categories like tense or person, can be negated and no grammatical distinctions are lost.

In asymmetric paradigms the correspondences between the paradigms used in affirmatives and negatives are not one-to-one; in almost all cases of paradigmatic asymmetry some grammatical distinctions made in the affirmative are lost (neutralized) in the negative, e. g., in Maung (4), where the distinction between realis and irrealis made in the affirmative is lost in the negative obligatorily marked as irrealis.

(4) Maung (Australia; Australian: Iwaidjan) (Capell and Hinch 1970: 67)
a. yi-udba
$1 \mathrm{SG}>3$-put
b. ni-udba-ji
$1 \mathrm{SG}>3$-put-IRR.NPST
'I put.'
c. marig ni-udba-ji
NEG $1 \mathrm{SG}>3$-put-IRR.NPST
'I do not put.', 'I cannot put.'

Constructional asymmetry is found in 83 out of a sample of 179 languages $(46 \%)$ and paradigmatic asymmetry in 53 languages $(30 \%){ }^{3}$

The Dravidian Zero Negatives show both constructional and paradigmatic asymmetry. ${ }^{4}$ The construction is asymmetric in that there are other structural differences between the affirmatives (1a) and (1b) and the negative (1c) than the presence of a negative marker, viz. the absence of tense marking. The paradigm is asymmetric in that the tense distinctions made in the affirmative (1a) and (1b) are lost in the negative (1c). Note that as there is no overt negator, the asymmetry (the absence of tense marking) serves as the indicator of the negative semantics of the clause.

It is not at all rare in the world's languages that the marking of grammatical categories in negatives is different from their marking in affirmatives. The categories that are affected the most often by asymmetry are tense-aspectmood (TAM) categories. Constructional asymmetry affecting the marking of tense-aspect-mood is found in 46 out of 179 languages (26\%), and in 44 out of 179 languages $(25 \%)$ there is paradigmatic asymmetry whereby some tense-aspect-mood distinction(s) available in the affirmative are excluded in the negative (these numbers only include instances in which negation affects the marking of tense-aspect-mood categories directly). ${ }^{5}$ It is not always straightforwardly clear whether a particular category in a language should be analysed as tense, aspect or mood, but it seems safe to say that tense distinctions are involved in well over a third of the paradigmatic cases. 
I will now discuss some examples of how tense-aspect-mood categories can be affected. As was already seen in the Maung example (4) above, irrealis mood may be obligatory under negation in some languages and the distinction between realis and irrealis may then be lost. A different type of neutralization happens in Páez (5), where the affirmative can make a distinction between Progressive and Habitual (5a) and (5b), but the negative suffix $\{-$ mex $\}$ cannot occur with the Habitual and only the Progressive form is available in the negative (5c); the paradigm is thus asymmetric. The construction is symmetric in that the only difference between the negative and the (Progressive) affirmative verb form is the presence of the negative marker (the absence of the final vowel in $(5 \mathrm{c})$ is due to an automatic phonological process and thus does not count as asymmetry in the relevant sense).

(5) Páez (Colombia; Páezan) (Jung 1989: 102-104) ${ }^{6}$

a. âts,h-a' ts,hab-na u'x-we-ts-thu now-TOP village-to go-IMPF-PROG-DECL.1SG

'I'm going to the village right now.'

b. skwela-na-t, u'x-we-' school-to-FACT.3PL go-IMPF-HAB

'They go to school.'

c. u'x-we-ts-me'-th go-IMPF-PROG-NEG-DECL.1SG 'I don't go.', 'I'm not going.'

In most of the languages in which some tense-aspect-mood distinctions made in the affirmative are lost in the negative, there still is some tenseaspect-mood marking in negatives, i.e. only some categories are excluded, as in Páez.

However, there are also a few cases in which the negative does not contain any tense-aspect-mood marking at all even though the corresponding affirmative does; in the 179-language sample there are three languages in which such a construction can be clearly identified. In one of the standard negation constructions available in Rama (example 6), the negative element yaana appears pre-verbally or clause-initially and the verb has no tense marking, i.e. the tense suffixes found in affirmatives (6a) and (6b) are absent in negatives (6c). In Imonda (example 7), postposed hoi is one of the means of expressing standard negation and with this negative marker tense marking does not appear on the verb. In Ogbronuagum (8), the Factitive, Future, and Progres- 
sive categories are negated by a construction in which the negative marker is fused with the subject proclitic and no tense-aspect-mood marker is present.

(6) Rama (Nicaragua; Chibchan: Rama) (Grinevald Craig, no date: 106, $145,190)$
a. nah sung-i
1 see-PRES
b. i-siik-u
'I see (it)'
'He came.'
c. yaana urnga ma-ni-tang
NEG food 2-1-give
'I am not going to give you food.'

(7) Imonda (Papua-New Guinea; Border) (Seiler 1985: 157, 172)
a. muit ale-la- $f$
Muit stay-EMPH-PRES
b. toad ale hoi
boys stay NEG
'Muit is here / there / in.'
'There were no boys.'

(8) Ogbronuagum (Nigeria; Niger-Congo: Cross-River) (Kari 2000: 34 35)
a. o-tó-lé akídı
1PL-FUT-eat beans
b. oji-móolv ínว
1PL.NEG-catch fish
'We shall eat beans.'
'We shall not catch fish.'

What these cases have in common with the Subtracting Zero Negative Construction is that tense-aspect-mood marking found in the affirmative is absent in the negative and the tense-aspect-mood distinctions in question are not available. ${ }^{7}$ The constructions are asymmetric as there is no non-negative form differing from the negative by the mere presence/absence of the negative marker, and the paradigms are also asymmetric in that some tense-aspectmood distinctions made in the affirmative are unavailable in the negative.

In the above examples, just as in Dravidian Zero Negatives, the verbal forms are finite in the sense that they are neither dependent on a higher verbal element nor verbal forms used as dependent forms in other contexts. There is a subtype of asymmetric negation in which the lexical verb loses its finiteness in the negative, and among these constructions one can find some more cases of absence of tense-aspect-mood marking in the negative. In Sentani (9), the negative marker is a vowel prefix, all verbal marking (tense-aspect-mood, person-number) is lost on the verb, and the verb appears in the Non-Temporal form, which is a non-finite form used in some dependent clauses as well. 
(9) Sentani (Indonesia: West Papua; Sentani) (Hartzler 1994: 52-53)

a. пеуæ u-eu-ne

he say-3SG.SUBJ.R-3SG.OBJ

'He is saying to him.'

b. o-boro-i

NEG-hear-NTMP

'I / you / he / she / we / you / they didn't / do(es)n't / won't hear.'

In Sentani the absence of tense-aspect-mood marking is not due to negation in the same sense as in the cases discussed earlier: the negative construction uses a non-finite form of the lexical verb, and because this non-finite form happens to lack tense-aspect-mood marking in this language, such marking is also absent in negatives. In negative constructions in which the lexical verb loses its finiteness, tense-aspect-mood marking is only rarely lost; it happens in only two more languages in the 179-language sample: Inanwatan and Rama (in a different construction from the one discussed above).

A few more cases of absence of tense marking may come about through the ellipsis of auxiliaries introduced to carry verbal inflections when the lexical verb loses its finiteness. In Apalaí, the negative marker - pyra appears on the lexical verb that becomes non-finite and the copula is introduced to carry tense and subject marking (10).

(10) Apalaí (Brazil; Cariban) (Koehn and Koehn 1986: 64)
a. isapokara [Ø]-ene-no
jakuruaru.lizard [1>3]-see-IMPST
'I saw a jakuruaru lizard.'
b. isapokara on-ene-pyra a-ken
jakuruaru.lizard 3-see-NEG 1-be.IMPST
'I did not see a jakuruaru lizard.'

The copula is, however, optional if the grammatical categories expressed by it are obvious from the context. Absence of tense-aspect-mood marking in negatives through the optional loss of copula in this type of negative construction can be found in seven of the 179 languages: Apalaí, Araona, Lower Grand Valley Dani, Quileute, Suena, Waorani and Yareba.

In this section I have shown that the loss of tense-aspect-mood distinctions in negatives is by no means unique to Dravidian languages (although the complete absence of tense-aspect-mood marking present in the corresponding 
affirmatives is rather uncommon). I will now turn to the much rarer aspect of the Dravidian negatives - the absence of an overt marker of negation.

\subsection{Negatives with no overt markers of negation}

As discussed above, Subtracting Zero Negative Constructions have not been found outside of the Dravidian family. The Raritätenkabinett suggests that such a construction might be found in two non-Dravidian languages, viz. Achumawi and Malakmalak, and a similar claim has also been made concerning Karitiâna. In this section I will examine all three cases, and discuss to which extent they fit the definition of the Subtracting Zero Negative Construction. Finally, I will take a look at negation in Igbo, which clearly does not show a Subtracting Zero Negative Construction, but comes closest to having no overt negative marker in standard negation in my 297-language variety sample.

\subsubsection{Malakmalak}

The Raritätenkabinett mentions Malakmalak as a possible case of Zero Negation. The source for this information is Forest (1993), but if we take a closer look at Forest (1993: 61-63) or the original source (Birk 1976), there is no reason to see a Subtracting Zero Negative Construction in this language. Negation can be expressed using a negative construction in which the negative particle (adverb) akana occurs preverbally (11).

(11) Malakmalak (Australia; Australian: Northern Daly) (Birk 1976: 124)

akana pilp yi-nma-nayi-wa

NEG slap 3SG.M.SUBJ-FUT-3SG.F.OBJ-FUT

'He will not slap her.'

Often, however, negative meaning is expressed with constructions whose primary function is not (pure) negation. The Adversative (marked by the suffixes -tan and -wur) is one of the means for expressing these indirect negatives. According to Birk (1976: 92), the Adversative "renders of no account the action described by the verb root to which it is suffixed". In (12a) we can see - $\tan$ in a sort of frustrative ("in vain") function and in (12b) it is translated as a negative. 
(12) Malakmalak (Australia; Australian: Northern Daly) (Birk 1976: $92-$ 93)

a. kay-tan a-ya-nö

call-AVR 1SG.SUBJ-PNCT-3SG.M.OBJ

'I called him but there was no reply.'

b. tikka-tan yö-nugka-kka

come.back-AVR 3SG.M.SUBJ-FUT-FOC

'He will not be coming back.'

Another inherently non-negative suffix, -manja, can be used as a negator in a restricted number of contexts. ${ }^{8}$ What is relevant for our concerns is that even if Malakmalak often expresses meanings that would be expressed with direct negatives in most other languages with less direct ways of negation, these categories are overtly marked, and clearly do not constitute parallels to the Dravidian Zero Negatives. The avoidance of explicit marking of negation is of a very different kind - functional (semantic / pragmatic) rather than formal as in the Subtracting Zero Negative Construction. Wintu (USA; Penutian: Wintuan) shows a similar kind of avoidance of the use of direct negatives (see Lee 1946).

A slightly different case may be found in Ungarinjin (Australia; Australian: Wororan; Rumsey 1982). In this language, negatives are obligatorily marked as irrealis, i. e. the negative particle occurs together with the irrealis form of the verb. But the irrealis form can occasionally be used with a negative meaning without a preceding negative particle. Is this then a negative without a negator? According to Rumsey (1982: 91), the irrealis form of the verb comes from an earlier negative form, i. e. a negative form has been reanalysed as irrealis. In the rare cases in which the irrealis form still expresses negation alone, it may perhaps be analysed as a negative marker as was the case at an earlier stage of the language. In any case, the category is overtly marked and thus clearly different from the Subtracting Zero Negative Construction.

\subsubsection{Achumawi}

In Achumawi (13), standard negation is expressed with a construction in which the lexical verb is nominalized, and the marker tsé- is attached to the existential copula which appears as the finite element of the clause. 
(13) Achumawi (USA; Hokan: Palaihnihan) (de Angulo and Freeland 1931: 97, 112)
a. S-ă'm-á
$1 \mathrm{SG}-\mathrm{eat}-\mathrm{FV}$
b. tsé-s-ùw-í d-ámm-ì
'I eat.'
NEG-1 SG-be-FV NMLZ-eat-FV
'I do not eat.'

According to Forest (1993: 53) there is no negative element in the construction - the element tsé-is taken to be a special participial form of the verb 'be'. However, nowhere in de Angulo and Freeland (1931; the source that Forest also uses) is $t s e ́$ - treated as a form of the verb 'be'. The following quote shows clearly that they treat it as a negative element (de Angulo and Freeland 1931: 112):

The "auxiliary" [form of the verb be] is used especially to form the negative, in connection with the element tsé- (to be classed as an "adjective"?). The combination is then followed by the Denominative form of the verb to be expressed negatively, thus; tsé-sùwí d-ámm-ì “I don't eat" (not-I-am eating)

Although they are not certain about the categorial status of tsé-, they clearly treat it as a negative element, glossing it as "not" and calling it "the ordinary negative" (de Angulo and Freeland 1931: 116) and "negative particle" (de Angulo and Freeland 1931: 117); they do not give any indication that it would be a form of the verb 'be'. ${ }^{9}$ There can be no other conclusion than that $t s e ́$ - is a negative marker.

However, if we look beyond standard negation in Achumawi, we can find constructions in which it seems to be the case that no overt marker of negation is present. The element nám '(not) yet' has positive meaning when followed by a verb with Indicative pronominal prefixes and negative meaning when Subordinate pronominal prefixes are found on the following verb (14).

(14) Achumawi (USA; Hokan: Palaihnihan) (de Angulo and Freeland 1931: 87)
a. nám y-ă’m-á
yet 3SG-eat-FV
'He is still eating.'
b. nám t-ă’m-á
yet 3SG.SBRD-eat-FV
'He is not eating yet.'

This is the only example of this construction found in the source, and there is no further information given. In a passage dealing with the Subordinate category (de Angulo and Freeland 1931: 89-90), we learn further that its functions are as follows: it is used in interrogatives, in complement clauses 
and to express the idea 'to have performed an action once before'. It is difficult to interpret nám as involving a negative element when it occurs in front of a Subordinate verb but not involving one in connection with an Indicative verb. On the basis of the information available in de Angulo and Freeland (1931), we may consider this to be a negative construction without negators. However, it is not an instance of Subtracting Zero Negative Construction, since it is not the case that the construction differs from the corresponding affirmative by the absence of marking of a category present in the affirmative the difference is in the use of a different set of subject prefixes (Subordinate instead of Indicative). Forest (1993: 17, citing Hilders and Lawrance 1957) mentions a similar construction from the Eastern Sudanic (Nilo-Saharan) language Teso.

A third construction to be discussed from Achumawi is the negation of the Periphrastic Future of Eventuality (15).

(15) Achumawi (USA; Hokan: Palaihnihan) (de Angulo and Freeland 1931: 112)
a. d-ù? má'd-ì'gú-s-ùw-á
NMLZ-sleep-PURP-1SG-be-FV
'I will be sleeping.'
b. d-ù ${ }^{2}$ má'd-ì'gú-d-ùts-ì-s-ùw-á
NMLZ-sleep-PURP-NMLZ-be-FV-1SG-be-FV

'I will not be sleeping.'

In this construction, negation is expressed by the addition of dìtsì, a nominalized form of the verb 'be', without the presence of any overtly negative element. According to de Angulo and Freeland (1931: 112, 116-117), this is due to the fact that the regular -ámè (negative after Denominatives) is not compatible with the Purposive -( $\left.\hat{i}^{*}\right) g u$ u A possible analysis would of course be to see dùtsì as the marker of negation in this particular construction, and the connection with the verb 'be' would then be only diachronic. Be it as it may, this construction is not an instance of Subtracting Zero Negative Construction, since morphemes are added rather than deleted when the affirmative is turned into a negative.

\subsubsection{Karitiâna}

According to Landin (1984: 1, 11-12), Karitiâna marks affirmatives overtly while negatives are unmarked, i. e. negatives differ from affirmatives by the 
absence of the Affirmative markers and no negative marker is present. Furthermore, tense-aspect suffixes are also absent in negatives. This is illustrated by the pair of examples in (16).

$$
\text { Karitiâna (Brazil; Tupian: Arikem) (Landin 1984: 11) }{ }^{10}
$$
a. $y$ ta-oty-j $\tilde{y} n$
1SG AFF-bathe-TNS $1 \mathrm{SG}$
'I will bathe.'
b. $y$ oty $\tilde{y} n$
1SG bathe $1 \mathrm{SG}$
'I will not bathe.'

Some further differences between affirmatives and negatives are also observed. In negatives containing a transitive verb the third person direct object pronoun $i$ - is inserted. In the case of intransitive stems with initial stress the epenthetic element $r y$ - appears, and on consonant-final stems the epenthetic element $-y$ is found. Thus in the case of vowel-final intransitives with noninitial stress, negatives seem to differ from the corresponding affirmative by the absence of the Affirmative marker (and tense marking).

Storto's analysis of Karitiâna negatives differs from Landin's and the essential differences can be briefly summarized as follows (Storto 1999 and p.c.). There is an overt negator in the negative construction, the postverbal element $\mathrm{pa}^{d} \mathrm{ni}$, but this element can also be omitted (17). ${ }^{11}$

Karitiâna (Brazil; Tupian: Arikem) (Storto 1999: 68-69)
a. i-soPort-o (pa $\left.{ }^{d} \mathbf{n}\right)$
3SG-see-EPN NEG
'(S)he didn't see.'
b. i-a-oki (pa $\left.{ }^{d} \boldsymbol{n} \tilde{\mathbf{I}}\right)$ 3SG-PASS-kill NEG
'(S)he wasn't killed.'

Since the prefixal markers that Landin calls Affirmative are absent not only in the negative, but also in some non-declarative contexts such as imperatives, interrogatives and quotes, they are analysed as Declarative mood markers, marking "a statement that the speaker believes to be true." (Storto 1999: 163, n. 56). Their absence does not signal negation.

Everett's (2006: 328-332) account is, again, different. He notes (Everett 2006: 329) that the negator $\mathrm{pa}^{d} \mathrm{ni}$ "can (and typically does) follow the verb in negative clauses", cf. (18d). Apart from this optional negator, intransitive and transitive verbs behave differently. In the case of vowel-final intransitives with non-inital stress, negation is unmarked (if $\mathrm{pa}^{d} n i$ is not used) (18a). Consonant-final intransitives receive the negative suffix $-\dot{i} /-\tilde{i}$ (18b) and (18c) and initially stressed intransitives may be prefixed with the negative marker ri- (18c); the elements treated as epenthetic elements by Landin and Storto are 
thus taken to be morphological negative markers. In transitive negatives the prefix $i$ - appears (18d). This element was analysed as a third person marker by both Landin and Storto, but Everett treats it as an irrealis marker, since it is also used in interrogatives and imperatives and is not restricted to third person contexts (see also Everett 2006: 253-256).

Karitiâna (Brazil; Tupian: Arikem) (Everett 2006: 255, 328-329) ${ }^{12}$
a. $\dot{\mathrm{i}}$-oti
1SG.ABS-bathe (1SG)

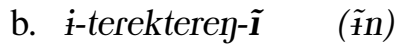
'I did not bathe.'
1SG.ABS-dance-NEG (1SG)
c. $\dot{\boldsymbol{i}}-\boldsymbol{r} \mathbf{i}-m b i k-\dot{\boldsymbol{i}} \quad \tilde{\boldsymbol{t}} \boldsymbol{n}$
1SG.ABS-NEG-Sit-NEG 1SG
'I did not dance.'
'I did not sit.'
e. i-ator-i $\tilde{i}$ in bĩpãn
IRR-take-FUT 1SG arrow.OBL
'I will not take the arrow.'
g. $\tilde{t} n$ na-opĩ $-t \quad(\tilde{t} n)$
1SG NSAP-cut-NFUT $1 \mathrm{SG}$
'I cut it.', 'I cut something.'
d. $\tilde{\text { tn }}$ i-soki padni eppa
1SG IRR-break NEG oar
'I did not break the oar.'
f. in i-opiso-t
1.ERG INTR-hear-NFUT
'I heard.'

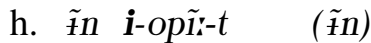
$1 \mathrm{SG}$ IRR-cut-NFUT $1 \mathrm{SG}$
'I did not cut it.', 'I did not cut.'

The markers analysed as Affirmative by Landin and Declarative by Storto are also treated differently by Everett (2006: 284-290, 409-424): he agrees with the earlier analyses that they are not used in negatives, imperatives and interrogatives, but does not consider them to be markers of mood. Instead, they are analysed as markers of voice, marking Speech-Act-Participant and Non-Speech-Act-Participant voices. Examples of affirmatives with and without the use of the Non-Speech-Act-Participant prefix can be seen in (18f) and (18g), cf. (18h). The examples in (18) also show that tense is not systematically absent in negatives, but tense marking varies according to the clausal construction used in a more complex way.

The Karitiâna data have been analysed in different ways by different authors. All these analyses point to the direction that there is an environment (vowel-final intransitives with non-inital stress) in which negation may be completely unmarked in case the postverbal negator is ellipted. In other contexts there is always an overt marker, although in the case of transitives, following Everett's analysis, the marker is not a dedicated negative marker but a more general irrealis marker (cf. the discussion of Ungarinjin on page 177). Contrasted with affirmatives marked with the (Non)-Speech-Act-Participant voice, example pairs can indeed be found in which the affirmative contains 
a marker and the negative differs from it by the absence of this marker, e. g., (16a) vs. (16b) on page 180 . These look very much like instances of Subtracting Zero Negative Construction. However, if the system is considered as a whole, Karitiâna cannot be said to use a Subtracting Zero Negative Construction to express negation.

\subsubsection{Igbo}

In Igbo, the basic tense-aspect-mood and polarity distinctions are made by the presence vs. absence of the vowel prefix and by varying tone. The (indicative) system shows a basic distinction between imperfective and perfective aspect. The imperfective has the prefix in the negative but not in the affirmative (19a), (19b), whereas in the perfective the opposite pattern is found, the prefix occurring in the affirmative but not in the negative (19c). ${ }^{13}$ Affirmatives and negatives also differ in their characteristic tone patterns.

(19) Igbo (Nigeria; Niger-Congo: Igboid) (Green and Igwe 1963: 75, 119, 140)

\section{a. anyì cì anz we carry bit.of.meat}

'We are (were) carrying bits of meat.'

b. anyi a-ci akhv we PFX-carry palm.nut

'We are (were) not carrying palm nuts.', 'We did not carry palm nuts.'

c. ĥhâ gà-rà I-cí akhv j̀fo á-cI-ta èkwè cì-tà-ghì they go-PST PFX-carry palm.nut Ofo PFX-carry-PST Ekwe carry-PST-EMPH 'They went to fetch some palm nuts. Ofo fetched some and Ekwe did not.'

With inseparable subject pronouns, the prefix is never used, and in such cases some distinctions are made by tone only cf. (20a) and (20b).

(20) Igbo (Nigeria; Niger-Congo: Igboid) (Green and Igwe 1963: 75, 119)
a. J cì anv
(s)he carry bit.of.meat

'(S)he is / was carrying bits of meat.' 
b. J cí akhv

(s)he carry palm.nut

'(S)he is / was not carrying palm nuts.', '(S)he did not carry palm nuts.'

The functional load carried by tone is high. Sometimes even the tonal patterns are identical, thus e.g. (20b) is ambiguous between a negative and an exclamative affirmative. Such ambiguities may arise in different parts of the verbal system, and various (non-inflectional) affixes can be used to disambiguate. Negatives often have the emphatic suffix -ghI, but this is not obligatory, and it can occur in the affirmative too (cf. Green and Igwe 1963: 60). ${ }^{14}$

Following the analysis of the basic aspectual and polarity distinctions outlined above, we may conclude that there is no overt segmental negator in Igbo - the distinction between affirmation and negation is expressed by the interaction of tone and presence vs. absence of prefix. Negatives have their own characteristic tone patterns and in this general sense we may say that these tone patterns are the overt markers of negation.

In practice, however, the same tone patterns may occur in different functions in different contexts (cf. the ambiguity of (20b)), and thus they are not dedicated markers of negation. The specific combination of proclitics and tones that occur in the negative marks the clauses as negative, but the same segmental elements and tone patterns have other functions in the verbal system as well. Discussing all the possible combinations in detail is beyond the scope of this paper, but the above discussion shows clearly that identifying a specific marker as an overt marker of negation is not straightforward in Igbo.

As I have argued in Miestamo (2005: 272), a similar situation obtains in Degema (Nigeria; Niger-Congo: Edoid). In terms of the symmetry-asymmetry distinction, we can say that, just as in the Dravidian Zero Negatives, the asymmetry alone renders the sentences negative in these languages.

\section{Ellipsis of negators}

Expression of negation without negators may come about through the ellipsis of negative markers. As already seen in example (3) on page 171, Finnish expresses negation with an asymmetric construction in which the negative marker is the negative auxiliary $e$ - carrying personal inflections, and the lexical verb appears in the Connegative form (which is formally an uninflected stem and does not contain any negative marking). 
Several authors, e.g., Savijärvi (1977, 1981), have reported that in their dialectal material, the negative auxiliary is sometimes ellipted (21).

(21) Häme dialect of Finnish (Finland; Uralic: Finnic) (Savijärvi 1977: 28)

su-lla muu-ta-ka tyä-tä o

2SG-ADE other-PART-NPI work-PART be.CNG

'(But) you have no other work either.'

The negative meaning is clear in (21), but no negative marker is present. The Connegative form of the verb and the negative polarity clitic $-k A$ are enough to convey negative force here. It should also be noted that even if we changed these elements into elements occurring in declarative affirmatives, the word order would not be possible for a positive statement, at least not in the context in which this clause has been uttered. There are thus enough clues that this is indeed a negative, although no overt negator is present.

Ellipsis of the negative auxiliary has also been reported from other Uralic languages, e. g., Estonian dialects (see Honti 1997: 165-166 and references therein; Klaus 2009).

Similar negatives without the negative auxiliary are found in contemporary spoken Finnish, and as Kotilainen (2007) observes, they are also increasingly attested in written language, being used frequently in internet chats, cf. (22).

(22) Colloquial Finnish (Finland; Uralic: Finnic) (Kotilainen 2007: 7)

$<$ cacha $>$ Tycho, mä töissä oo!! :O

$<$ cacha $>$ Tycho mä tö-i-ssä oo $\quad: O$

NAME NAME 1 SG work-PL-INE be.CNG :O

'<cacha $>$ Tycho, I'm not at work!! :O'

In (22) the negative meaning is again clear, although no overt marker of negation is present. The Connegative form of the verb is enough to express the negative meaning here, and again, word order is different from any felicitous positive expression in the same context. Kotilainen (2007) points out that these constructions occur as a strong reaction to what has been said before, cf. the exclamation marks and the shouting smiley in (22). According to him, this is not a case of ellipsis of the negative auxiliary in contemporary Finnish, but has been conventionalized as a special affective negative construction.

Summarizing, negatives without overt negation can be found in Finnish either due to ellipsis of the negator or in a special affective construction, and 
the other structural differences between negatives and affirmatives then convey negative meaning. However, in contrast to the Dravidian Zero Negatives, these are not instances of standard negation, i. e. they do not belong to the basic means Finnish employs for the simple/neutral negation of declarative verbal main clauses. Furthermore, they do not fall under the definition of the Subtracting Zero Negative Construction, since negation is not expressed by subtraction of material present in the affirmative.

Ellipsis of negative marking has also been reported from the Australian language Nunggubuyu. There is extensive structural asymmetry between affirmatives and negatives in this language: affirmatives and negatives differ in realis-irrealis marking, most negatives being obligatorily irrealis-marked, and there are some other differences in the marking of verbal categories as well; furthermore, nouns and demonstratives in the scope of negation also show different behaviour from the affirmative, see Heath (1984: 526) for a summary and Miestamo (2005: 106-108, 328-329, 429-430) for discussion. According to Heath (1984: 531), the negative marker is sometimes ellipted, and then the asymmetries serve to mark negation alone.

This section has shown that in some languages in which negation is asymmetric, the negative marker may sometimes fall out and the asymmetries can then distinguish these negative clauses from affirmatives without the presence of an overt marker of negation. I have not encountered this in the grammars of any other language of my sample. This may be because the phenomenon is indeed very rare. I would, however, tend to think that it might be somewhat more widespread, but as its textual frequency is low in the languages in which it occurs, descriptive grammarians usually either ignore it or leave it out as a marginal phenomenon.

\section{Discussion}

\subsection{Functional motivations}

In this section I will address the functional motivations behind the Dravidian Zero Negatives. I will start from the motivations for the loss of tense distinctions and discuss the absence of tense marking further below. The following principles are proposed as general motivations for the cross-linguistically recurrent types of negative structures in (Miestamo 2005: Ch. 5): Symmetric negatives are language-internally analogous to the affirmative, copying its linguistic structure; they are ultimately motivated by pressure for system cohe- 
sion. Asymmetric negatives copy different aspects of the functional asymmetry between affirmation and negation and are thus language-externally analogous to these functional-level asymmetries (for the notions of languageinternal and language-external analogy, see also Itkonen 2005). The specific functional-level asymmetry proposed as explanation for the existence of paradigmatic asymmetry in which grammatical distinctions are lost in negatives, i. e. the type also represented by the Dravidian Zero Negatives, emerges from the discourse context of negation. ${ }^{15}$

Negatives are typically used as denials of propositions that are in some sense present in the context, so when negatives are uttered, their temporal and other properties are usually familiar to the speaker and hearer and need not be further specified. In some languages this has grammaticalized as obligatory neutralization of (some) grammatical distinctions in the negative. Another functional level asymmetry between affirmatives and negatives that can contribute to the loss of grammatical distinctions in the negative is that it is often more difficult and less relevant to attribute temporal and other specifications to non-realized, e. g., negated, events than to realized ones.

Concerning the absence of negative marking in Dravidian, many authors (e. g., Pederson 1993) have argued that the Zero Negatives have come about through phonological erosion of the negative marker. According to PilotRaichoor (1997, 2010), the phonological erosion account is not plausible, since all hypotheses following that line in the literature contain some unresolved problems and controversies. She argues that the construction has a semantic motivation linked to the specific meanings of the Dravidian tense morphemes, and that favourable conditions for its structural development were created by the shift from analytic to synthetic type that the languages underwent in that historical period. Not being a Dravidianist, I will not engage in a detailed discussion of the history of the Dravidian construction, but keep my focus on the typological perspective.

There is one way in which typological investigations could lend support to Pilot-Raichoor's account: demonstrating that the type of tense-aspect-mood semantics found in Dravidian correlates with the presence of a Subtracting Zero Negative Construction. A typological investigation charting the crosslinguistic frequency and distribution of such tense-aspect-mood meanings is beyond the scope of the present study. But even if this information were available, no such correlation could be demonstrated since Subtracting Zero Negative Constructions are not found in any non-Dravidian language. In this light, one must agree with Pilot-Raichoor's conclusion that the uniqueness of the 
Dravidian Zero Negative construction is due to the rarity of the simultaneous occurrence of all the factors conditioning its development - a situation underlying most (if not all) rara and rarissima.

We have seen that the absence of negative markers is very rare. Tense and aspect distinctions are commonly lost in negatives, and in some languages, the tense-aspect-mood markers present in the affirmative are completely absent in the negative. Yet, in all these cases, except in the Dravidian Zero Negatives, there is overt marking of negation. This conforms to the observation, which has been common knowledge at least since Jespersen (1917), that negatives very often need reinforcement and tend to be expressed by more, rather than less, phonetic material. The best known example of the effects of this need is the development of negation, e.g., in English and French, commonly referred to as Jespersen's Cycle, whereby emphatic elements are needed to make negative meaning more explicit and these elements are then reanalysed as negative markers, which may later allow for the phonetic reduction and loss of earlier negative elements. And indeed, the need for reinforcement is doing its work in Igbo as well (cf. Section 3.2.3): the emphatic suffix seems to be becoming an overt negative marker used with the constructions containing no dedicated segmental markers of negation. The ultimate motivation for the need for reinforcement comes from the discourse context of negatives: as the prototypical use of negation is denial of semantic contents that are implicitly or explicitly present in the context, they often constitute somewhat abrupt speech acts, and therefore need emphasis on the negativity (see Miestamo 2005: 197-199, 209-210 for more discussion). The Dravidian Zero Negatives go drastically against this well-motivated tendency.

Coming back to the cases of ellipsis in Section 4, since constructions first arise in performance and only later conventionalize as grammatical constructions, the ellipsis of negators may indeed provide a source for negatives without negators. However, as negation needs clear and often emphatic expression, the elliptic cases cannot easily develop into grammatical constructions as such, and a new negative element is likely to emerge to make sure that negative force is conveyed. Concerning the newly conventionalized affective negative construction without overt negator in Finnish (see example (22) on page 184), Kotilainen (2007) suggests that the pronominal negative polarity item mitään 'anything' might be on its way to becoming a negative marker in this construction (cf. the Estonian negative element mitte which is etymologically the same element). 


\subsection{Negatives without negators and typological markedness}

The foundations of the typological conception of markedness were laid by Greenberg (1966). Following Croft (2003), the criteria for typological markedness can be reduced to overt coding, behavioural potential and frequency. ${ }^{16}$ According to the overt coding criterion, the marked category is expressed by at least as many morphemes as the unmarked one. Behavioural potential is divided into two criteria: on the one hand, the paradigmatic potential of the unmarked category is at least as high as that of the marked one, i. e. at least as many grammatical distinctions can be made in connection with the unmarked category as with the marked one, and on the other, the distributional potential of the unmarked category is at least as high as that of the marked one, i. e. the unmarked category may itself be embedded in at least as many contexts as the marked one. Finally, according to the frequency criterion, the unmarked category occurs at least as frequently as the marked one.

The frequency criterion is not of interest here, since there is certainly no reason to expect that a standard negation construction without an overt marker of negation would behave differently from one with overt negators with respect to the textual frequency of negatives vs. affirmatives - affirmatives are more frequent than negatives no matter how negation is expressed. The behavioural criteria are more interesting in this context, since the Dravidian Zero Negatives do indeed show negatives as more marked than affirmatives: more grammatical distinctions are made in the affirmative than in the negative (just as in the numerous cases in which grammatical distinctions are unavailable in the negative discussed in Section 3.1). In this context, the most interesting criterion is overt coding, as some have claimed that the Dravidian Zero Negatives constitute a counterexample to the markedness of negation vis-à-vis affirmation in this sense.

It is true that there is more phonological and morphological material in the Old Kannada affirmative verb forms (1a) and (1b) on page 170 than in the negative (1c), and if we look at the whole verb form, we may say that the affirmative is coded by a longer form; but this is not what the overt coding criterion is about. There is no overt marking of affirmation either - the tense markers express tense-aspect-mood, not affirmation - and since the overt coding criterion says that the marked category is expressed by at least as many morphemes as the unmarked one, a situation in which neither category is overtly marked is not in conflict with the markedness of negation. Polarity - either affirmative or negative - is not overtly coded in any morpheme in the verb, 
and what we are dealing with here is a global constructional meaning carried by the whole verb form; this is also true of the other cases of negation without negators discussed in this paper.

In conclusion, the Dravidian Zero Negatives do not constitute counterevidence to the markedness of negation on the overt coding criterion either. There are no languages, Dravidian or other, in which (non-emphatic) affirmation receives overt marking while negation is unmarked (see Miestamo 2007 for more discussion on the typological markedness of negation).

\section{Conclusion}

In this paper, I have discussed, from a typological perspective, the Dravidian Zero Negative construction, or more generally the Subtracting Zero Negative Construction - a construction in which no overt marker of negation appears and the construction differs from the corresponding affirmative by the absence of marking of categories present in the affirmative. I have shown that it is indeed unique to Dravidian. That tense-aspect-mood distinctions are lost is not in itself rare, but expressing negation without any overt marker of negation is, and the combination of these two features makes the Dravidian construction unique. I have shown that, very rarely, negation can be expressed without overt negators in some other languages as well, but these constructions are clearly different from the Dravidian Zero Negatives. I have also discussed some suggested cases of zero negation that turn out not to be such. I have looked at the ellipsis of negators, and finally, I have examined the functional motivations behind negatives without negators and discussed these negatives from the point of view of typological markedness.

As an overall conclusion to this paper, I would like to reformulate the answers to two questions: First, why are negatives without negators rare? My view is that negatives make strong speech acts and need strong expression; it is not communicatively efficient to express negation only covertly. Why, then, are negatives without negators possible in the first place? My answer to this question is that there is functional asymmetry between affirmation and negation, and this grammaticalizes as structural asymmetry in many languages; this structural asymmetry provides other cues to identify negation in addition to the presence of overt negative markers, and thus enables negation without negators in some rare cases. 


\begin{abstract}
Abbreviations
$1=$ first person; $2=$ second person; $3=$ third person; $\mathrm{ABS}=$ absolutive; $\mathrm{ADE}=$ adessive; $\mathrm{AFF}=$ affirmative $; \mathrm{AVR}=$ adversative $; \mathrm{CNG}=$ connegative $; \mathrm{DECL}=$ declarative; $\mathrm{EMPH}=$ emphatic $; \mathrm{EPN}=$ epenthetic $; \mathrm{ERG}=$ ergative $; \mathrm{F}=$ feminine; $\mathrm{FACT}=$ factative $\mathrm{FOC}=$ focus $; \mathrm{FUT}=$ future $; \mathrm{FV}=$ final vowel $; \mathrm{HAB}=$ habitual; IMPST = immediate past; IMPF = imperfecive; INE = inessive; INTR = intransitive; IRR = irrealis; $\mathrm{M}=$ masculine; $\mathrm{NAME}=$ proper name; $\mathrm{NEG}=$ negative; $\mathrm{NFUT}=$ non-future; NMLZ = nominalization; NPI $=$ negative polarity item; NPST $=$ nonpast; NSAP $=$ non-speech-act-participant; NTMP $=$ non-temporal; OBJ $=$ object; $\mathrm{OBL}=$ oblique PART $=$ partitive $; \mathrm{PASS}=$ passive PERF $=$ perfect PFX = prefix; $\mathrm{PL}=$ plural; $\mathrm{PLUPERF}=$ pluperfect $; \mathrm{PNCT}=$ punctual $; \mathrm{PRES}=$ present $; \mathrm{PROG}=$ progressive PST = past PURP = purposive $; \mathrm{R}=$ realis; $\mathrm{SBRD}=$ subordinate $; \mathrm{SG}=$ singular; $\mathrm{SUBJ}=$ subject; $\mathrm{TNS}=$ tense; $\mathrm{TOP}=$ topic
\end{abstract}

\title{
Acknowledgments
}

I wish to thank my audience at the Rara \& Rarissima conference and the editors of this volume for their useful comments on the manuscript. The research reported here has been conducted at the universities of Helsinki and Antwerp, and financed by these universities and the Academy of Finland; the support of these institutions is gratefully acknowledged.

\section{Notes}

1. See http://typo.uni-konstanz.de/rara/intro/

2. For each language the main geographical location and genealogical affiliation (family: genus) is given following the classification by Dryer (2005) in The World Atlas of Language Structures.

3. The numbers given in this section are based on a 179-language subsample of the 297language variety sample. The subsample is areally and genealogically balanced so that each continent-size linguistic area (macroarea) is represented in proportion to its internal genealogical diversity (see Miestamo 2005: 35-36 for details).

4. Although the subtypes of asymmetric negation proposed in Miestamo (2005) are not discussed in this paper, it may be interesting for some readers to note that the constructional and paradigmatic asymmetry in the Dravidian Zero Negatives belongs to type A / Cat / TAM

5. To be more precise, these numbers only concern the subtypes of asymmetric negation labelled A/NonReal and A/Cat/TAM in Miestamo (2005), in which the asymmetry affects tense-aspect-mood categories directly: 10 of the 44 cases of neutralization are of 
subtype A / NonReal and 34 are of subtype A / Cat / TAM (see Miestamo 2005: 179-180); 8 languages show constructional asymmetry of subtype A/NonReal and 39 show constructional asymmetry of subtype A/Cat/TAM, one language, viz. Warndarang, showing both types (see Miestamo 2005: 173, 175, 360). In the other subtypes there are some cases in which the marking of tense-aspect-mood categories is affected indirectly, e.g., the Sentani construction to be discussed in example (9) on page 175.

6. The comma marks palatalization in Jung's orthography.

7. Note, however, that in both Imonda and Rama there are other negative constructions in connection with which tense-aspect-mood marking does appear, and in Ogbronuagum, as well, overt tense-aspect-mood marking appears in the perfect negative construction.

8. This is actually a combination of two suffixes both of which have a primary function characterizable as elative: - $m a n^{y}$ 'departing from', -na 'away from the speaker' (see Birk 1976: 87, 91-95, 105, 114).

9. The element tsé- occurs in the same position prefixed to the copula as many adjective stems (de Angulo and Freeland 1931: 85); formally it might then be classified as an adjective. Phonetically it does resemble some forms of the verb 'be' but not even a diachronic link to the verb be is suggested in the source. The participle of 'be' is tìdzí. Even if there were a diachronic link, it would still clearly be a negative element in the synchronic analysis of the construction.

10. The page numbers refer to the pagination in the version downloaded from the internet.

11. Landin (1984: 15) also mentions this element but according to him, it only occurs in negative sentences used as responses to polar questions.

12. In the original source, the gloss of (18c) lacks the negative elements, but a comparison with the text and with the glosses of the other examples makes it is obvious that this is a typographic error.

13. The alternative perfective translations of the negated imperfectives in (19b) and (20b) are due to the fact that the negative perfective cannot occur in an isolated utterance or initiating discourse, and the aspectual distinction is neutralized in these contexts.

14. In fact, Emenanjo (1987: 172) treats it as a negative suffix but says it "may be optionally deleted at the surface structure level".

15. Those cases of neutralization in which the negative is obligatorily marked as irrealis or some other non-realized category are of course more directly motivated by the fact that negation itself belongs to the non-realized (cf. Miestamo 2005: 208-209).

16. Croft speaks about the "structural criterion", but I find the term "overt coding criterion" clearer. Similarly, Croft uses the term "inflectional potential" for one of the behavioural potential criteria, but I prefer "paradigmatic potential" which is more neutral about the coding means by which the paradigmatic choices are expressed.

\section{References}

Birk, David. B. W.

1976 The Malakmalak Language, Daly River (Western Arnhem Land). (= Pacific Linguistics; B-45). Canberra: Australian National University.

Capell, Arthur, and H. E. Hinch

1970 Maung Grammar. (= Janua Linguarum, Series Practica; 98). The Hague: Mouton. 
Croft, William

2003 Typology and Universals. 2nd edition. Cambridge: Cambridge University Press.

de Angulo, Jaime, and L. S. Freeland

1931 The Achumawi language. International Journal of American Linguistics 6: 77-120.

Dryer, Matthew S.

2005 Genealogical language list. In The World Atlas of Language Structures, Martin Haspelmath, Matthew S. Dryer, David Gil, and Bernard Comrie (eds.), 584644. Oxford: Oxford University Press.

Emenanjo, E. Nolue

1987 Elements of Modern Igbo Grammar: A Descriptive Approach. Ibadan: University Press.

Everett, Caleb

2006 Gestural, perceptual, and conceptual patterns in Karitiana. Doctoral dissertation, Rice University.

Forest, Robert

1993 Négations: Essai de syntaxe et de typologie linguistique. (= Collection Linguistique; LXXVII). Paris: Klincksieck.

Green, M. M., and G. E. Igwe

1963 A Descriptive Grammar of Igbo. London: Oxford University Press.

Greenberg, Joseph

1966 Language Universals, with Special Reference to Feature Hierarchies. The Hague: Mouton.

Grinevald Craig, Colette

no date A grammar of Rama. Report to National Science Foundation BNS 8511156.

Hartzler, Margaret

1994 Sentani. In Typological Studies in Negation, Peter Kahrel and René van den Berg (eds.), 51-64. (= Typological Studies in Language; 29). Amsterdam: Benjamins.

Heath, Jeffrey

1984 Functional Grammar of Nunggubuyu. Canberra: Australian Institute of Aboriginal Studies.

Hilders, John H., and Jeremy C. D. Lawrance

1957 An Introduction to the Ateso Language. Kampala: Eagle Press.

Honti, László

1997 Die Negation im Uralischen II. Linguistica Uralica 1997 (3): 161-176.

Itkonen, Esa

2005 Analogy as Structure and Process: Approaches in Linguistics, Cognitive Psychology and Philosophy of Science. (= Human Cognitive Processing 14). Amsterdam: Benjamins.

Jung, Ingrid

1989 Grammatik des Paez, ein Abriss. Doctoral dissertation, University of Osnabrück. 
Kari, Ethelbert E.

2000 Ogbronuagum (The Bukuma Language). (= Languages of the World / Materials; 329). München: Lincom Europa.

Klaus, Anneliis

2009 Eitus eesti murretes [Negation in Estonian dialects]. MA thesis, Tartu University.

Koehn, Edward, and Sally Koehn

1986 Apalai. In Handbook of Amazonian Languages, vol. 1, Desmond C. Derbyshire, and Geoffrey K. Pullum (eds.), 33-127. Berlin/New York: Mouton de Gruyter.

Kotilainen, Lari

2007 Kiellon lumo. Kieltoverbitön kieltokonstruktio ja sen kiteytyminen. [The fascination of negation. The negative construction without negative verb and its crystallization] (= Suomi; 193). Helsinki: Suomalaisen Kirjallisuuden Seura.

Landin, David J.

1984 An outline of the syntactic structure of Karitiâna sentences. In Estudos sobre línguas tupí do Brasil, Robert A. Dooley (ed.), 219-254. (= Série Lingüística; 11). Brasilia: Summer Institute of Linguistics.

http://www.sil.org/americas/brasil/publens/ling/KTStruct.pdf

Lee, D. Demetracopoulou

1946 Stylistic use of the negative in Wintu. International Journal of American Linguistics 12.2: 79-81.

Master, Alfred

1946 The Zero Negative in Dravidian. Transactions of the Philological Society 1946: 137-155.

Miestamo, Matti

2005 Standard Negation: The Negation of Declarative Verbal Main Clauses in a Typological Perspective. (= Empirical Approaches to Language Typology; 31). Berlin / New York: Mouton de Gruyter.

Miestamo, Matti

2007 Symmetric and asymmetric encoding of functional domains, with remarks on typological markedness. In New Challenges in Typology: Broadening the Horizons and Redefining the Foundations, Matti Miestamo, and Bernhard Wälchli (eds.), 293-314. (= Trends in Linguistics, Studies and Monographs; 189). Berlin/ New York: Mouton de Gruyter.

Pederson, Eric

1993 Zero Negation in South Dravidian. In CLS 27, Papers from the 27th Regional Meeting of the Chicago Linguistic Society 1991, Part Two: The Parasession on Negation, Lise M. Dobrin, Lynn Nichols, and Rosa M. Rodriguez (eds.), 233-245. Chicago: Chicago Linguistic Society.

Pilot-Raichoor, Christiane

1997 Le zéro négatif dans les conjugaisons dravidiennes. Faits de langues 10: 77102. 


\section{Matti Miestamo}

Pilot-Raichoor, Christiane

2010 The Dravidian zero negative: Conceptualisation and diachronic context of its morphogenesis. In Rara \& Rarissima: Documenting the fringes of linguistic diversity, Jan Wohlgemuth and Michael Cysouw (eds.), 267-304. (= Empirical Approaches to Language Typology; 46). Berlin/New York: Mouton de Gruyter.

Rumsey, Alan

1982 An Intra-Sentence Grammar of Ungarinjin, North-Western Australia. (Pacific Linguistics; B-86). Canberra: Australian National University.

Savijärvi, Ilkka

1977 Redundanssi ja kieltoverbin ellipsi suomen kielen negaatiojärjestelmässä. [Redundancy and the ellipsis of the negative verb in the Finnish negation system] (= Jyväskylän yliopiston suomen kielen ja viestinnän laitoksen julkaisuja; 14). Jyväskylä: Jyväskylän yliopisto.

Savijärvi, Ilkka

1981 Redundanz und Ellipse des Negationsverbs im Negationssystem der finnischen Dialekte. In Heutige Wege der finnischen Dialektologie, Heikki Leskinen (ed.), 157-174. (= Studia Fennica; 24). Helsinki: Suomalaisen kirjallisuuden seura.

Seiler, Walter

1985 Imonda, A Papuan Language. (= Pacific Linguistics; B-93). Canberra: Australian National University.

Storto, Luciana

1999 Aspects of a Karitiana grammar. Doctoral dissertation, Massachusetts Institute of Technology.

Subrahmanyam, P. S.

1971 Dravidian Verb Morphology (A Comparative Study). (Annamalai University, Department of Linguistics. Publication 24) Annamalainagar: Annamalai University. 